\title{
Management of thoracoepigastric flap necrosis in patients with breast cancer
}

\author{
Manejo de la necrosis del colgajo toracoepigástrico en pacientes con cáncer de mama
}

\author{
Arife Simsek* \\ Department of General Surgery, School of Medicine, Inonu University, Malatya, Turkey
}

\begin{abstract}
Thoracoepigastric flap is rarely used for reconstruction of the large chest wall defects due to potential for necrosis and delayed wound healing. This article presents three patients with breast cancer, who underwent mastectomy and chest wall reconstruction with thoracoepigastric flap and subsequently developed distal flap necrosis. The negative pressure wound therapy may eliminate the need for additional graft and/or flap surgery in patients with large necrosis size.
\end{abstract}

Key words: Breast cancer. Chest wall defect. Flap necrosis. Negative pressure wound therapy. Thoracoepigastric flap.

\section{Resumen}

El colgajo toracoepigástrico rara vez se utiliza para la reconstrucción de grandes defectos de la pared torácica debido al potencial de necrosis y al retraso en la cicatrización de la herida. En este artículo se presentan tres pacientes con cáncer de mama, que fueron sometidas a mastectomía y reconstrucción de la pared torácica con colgajo toracoepigástrico y posteriormente desarrollaron necrosis del colgajo distal. La terapia de presión negativa para heridas puede eliminar la necesidad de cirugía adicional de injerto y/o colgajo en pacientes con necrosis de gran tamaño.

Palabras clave: Câncer de mama. Defecto de la pared torácica. Necrosis del colgajo. Terapia de heridas con presión negativa. Colgajo toracoepigástrico.

\section{Introduction}

Large chest wall defects develop secondary to tumor resection, radiotherapy, trauma, and infection'. Pedicled muscle or myocutaneous flaps are usually preferred instead of fasciocutaneous flaps to guarantee sufficient blood supply ${ }^{1}$. Thoracoepigastric flap, a form of fasciocutaneous flap, has random blood supply to the distal portion with the potential for necrosis and delayed wound healing ${ }^{2}$. The distal flap necrosis has been reported up to $60 \%$ (range: $0-60 \%$ ) in the literature ${ }^{2-4}$. It requires more wound dressing, debridement, and skin grafting, which, in turn, leads to prolonged length of stay in hospital. Consequently, technical aspect of these flaps is essential for surgeons, which in some cases are very useful ${ }^{2}$.

This study presents three patients with breast cancer, who underwent mastectomy and chest wall

\footnotetext{
Correspondence:

*Arife Simsek

Bulgurlu, Bulgurlu Mahallesi, Elazığ Yolu 15. Km.

Date of reception: 14-12-2020

C.P: 44280 , Malatya, Turkey

E-mail: draksimsek@yahoo.com.tr

0009-7411/@ 2021 Academia Mexicana de Cirugía. Published by Permanyer. This is an open access article under the terms of the CC BY-NC-ND license (http://creativecommons.org/licenses/by-nc-nd/4.0/).
} 
reconstruction with thoracoepigastric flap and subsequently developed distal flap necrosis.

\section{Case presentation}

\section{Flap technique}

The flap incision commenced at the inferior border of the mastectomy defect extending from the sternal border to the posterior axillary line, then proceeded down to the area of the anterior superior iliac spine (ASIS) (Fig. 1A). Perforators of the superior epigastric vessels were preserved (medially-based thoracoepigastric flaps). In the patient with bilateral breast cancer incision was extended to the point between the middle and the lower $1 / 3$ of the line from umbilicus to symphysis pubis to facilitate cephalad flap transposition. Perforators of the both superior and inferior epigastric vessels were preserved in that case. The flaps were elevated (from lateral to medial portion) with the inclusion of the deep fascia (Fig. 1B) and the donor areas were closed primarily without grafting in all cases.

\section{Case I}

Fifty-three-year-old woman with T4 metastatic breast cancer suffered from rapid tumor necrosis accompanied by massive hemorrhage that required blood transfusion (Fig. 2A). She continued to receive chemotherapy (CT) and hormonal therapy (HT). Modified radical mastectomy (MRM) was performed. The inferior border of the incision was below the submammary fold at the $8^{\text {th }}$ intercostal space, lateral border was extending to the middle axillary line, medial border to the midline of the sternum superior border to the $4^{\text {th }}$ costae. The chest wall defect $(40 \times 27 \mathrm{~cm})$ was reconstructed by medially based thoracoepigastric flap. The necrosis (size $2 \times 3 \mathrm{~cm}$ ) appeared in the distal portion of the flap within 3 days after surgery which, in turn, conservatively treated (Fig. 2B). Unfortunately, she died from liver metastasis within 3 months after surgery. The table 1 shows the patients' characteristics.

\section{Case II}

Forty-three-year-old woman with T4 metastatic breast cancer had restrictions in range of motion of shoulder with severe lymphedema of the left arm. The

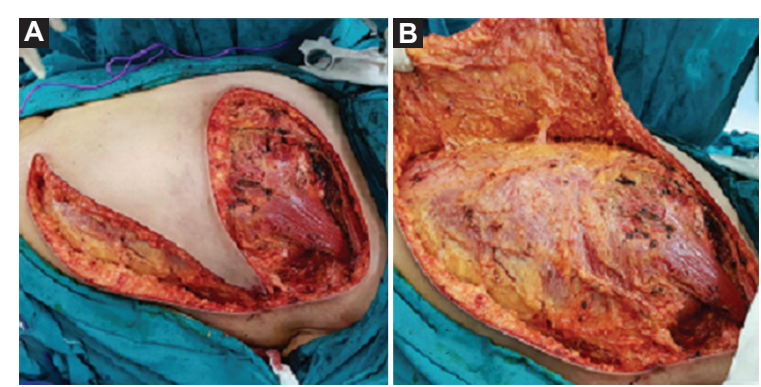

Figure 1. A: thoracoepigastric flap incision. B: thoracoepigastric flap elevation.

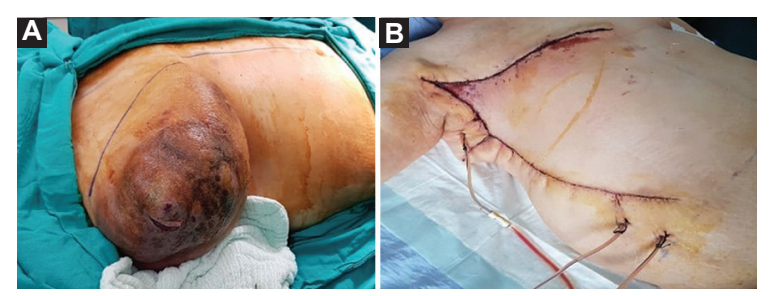

Figure 2. A: the pre-operative view of the Patient I. B: patient I was treated by conservative therapy.

foul odor emanating from her necrotic breast had resulted in her social withdrawal. She continued to receive CT and HT. Radical mastectomy was performed. The inferior border of the incision was below the submammary fold at the $8^{\text {th }}$ intercostal space, lateral border was extending to the middle axillary line, medial border to the midline of the sternum, and superior border to the clavicle. The chest wall defect $(30 \times$ $35 \mathrm{~cm}$ ) was reconstructed by medially based thoracoepigastric flap. The necrosis (size $15 \times 2 \mathrm{~cm}$ ) appeared in the distal portion of the flap within 5 days after surgery. The negative pressure wound therapy (NPWT) was applied on post-operative day 5 and renewed 4 times in 2 weeks, with intermittent pressure (35-50 $\mathrm{mm} \mathrm{Hg}$ ). The necrosis resolved completely and granulation tissue matrix filled the wound, which led to heal by second intention without requiring any graft. Daily dressings were sufficient for wound healing (Fig. $3 \mathrm{~A}$ and $\mathrm{B}$ ).

\section{Case III}

Fifty-one-year-old woman with T4 metastatic bilateral breast cancer continued to receive CT and HT. Bilateral MRM was performed. The inferior border of the incision was below the submammary fold at the $8^{\text {th }}$ intercostal space, lateral border was extending to 
Table 1. Characteristics of the patients

\begin{tabular}{llll}
\hline Characteristics & Case I & Case II & Case III \\
\hline Age (year) & 53 & 41 & 51 \\
Co-morbidity & Hypertension & - & Hypertension, Diabetes Mellitus \\
BMI & 36 & 33 & 44 \\
Bilateral cancer & - & - & + \\
Histopathology & Clear cell ca & Invasive ductal ca & Invasive ductal ca \\
Molecular subtype & Triple negative & Luminal A & Luminal B \\
T stage & T4 & T4 & T4 \\
Stage & IV & IV & IV \\
Metastasis & Liver, Bone & Mediastinum & Liver, Bone, Mediastinum \\
Breast surgery & MRM & Radical mastectomy & Bilateral MRM \\
Flap surgery & Thoracoepigastric & Thoracoepigastric & Extended \\
Defect size $(\mathrm{cm})$ & $40 \times 27$ & $30 \times 35$ & Bilateral Thoracoepigastric \\
Necrosis size $(\mathrm{cm})$ & $3 \times 2$ & $15 \times 2$ & $60 \times 40$ \\
Treatment & Conservative & NPWT & $50 \times 8$ \\
\hline B & & NPWT
\end{tabular}

*BMI: body mass index, MRM: modified radical mastectomy, NPWT: negative pressure wound therapy.

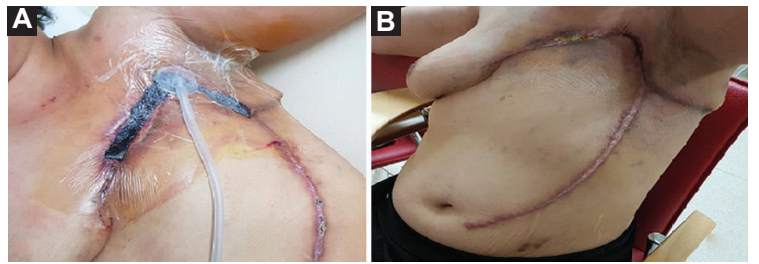

Figure 3. A: patient II was treated by negative-pressure wound therapy. B: the view of the patient II after negative-pressure wound therapy.

the middle axillary line, and superior border to the $2^{\text {nd }}$ costae. Since the medial border exceeded the sternum the specimen was removed en bloc bilaterally. The chest wall defect $(60 \times 40 \mathrm{~cm})$ was reconstructed by medially based thoracoepigastric flap bilaterally. The necrosis (size $50 \times 8 \mathrm{~cm}$ ) appeared in the distal portion of the flap within 7 days after surgery. The NPWT was applied on post-operative day 7 and renewed for 7 times in 4 weeks, with intermittent pressure $(50-75 \mathrm{~mm} \mathrm{Hg})$. The necrosis resolved completely and granulation tissue matrix filled the wound, which led to heal by second intention, without requiring any graft (Fig. 4A and B). Daily dressings were sufficient for wound healing after NPWT. Unfortunately, she died

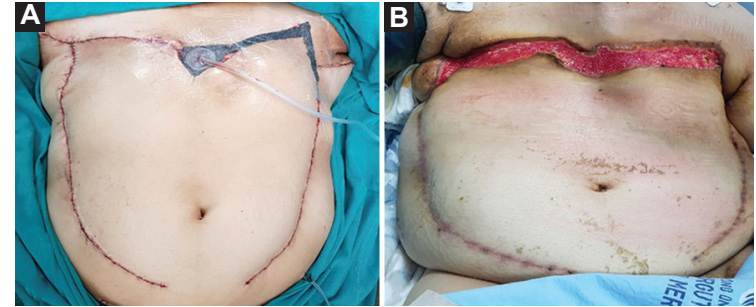

Figure 4. A: patient III was treated by negative-pressure wound therapy. B: the view of the patient III after negative-pressure wound therapy.

from pulmonary metastasis within 3 months after surgery.

\section{Discussion}

The patients with locally advanced breast cancer have a poor prognosis and extensive necrotizing wounds that cause pain, bleeding, and infection. Surgery is unavoidable in some patients to overcome these clinical conditions. In this study, one of three patients suffered from rapid tumor necrosis, which is accompanied by massive bleeding requiring blood transfusion, others had infected tumors, which led to 
their social withdrawal due to foul odor. The surgeons have to make sure that reconstruction of the thoracic wall defect, which emerging after breast surgery, is the best that they can offer to refer the patients to adjuvant therapy without further delay.

Chest wall reconstruction may include chest wall stabilization and/or soft-tissue reconstruction depending on whether the defect is full thickness or partial thickness ${ }^{5}$. The reconstruction with pedicled muscle or myocutaneous flaps is the most popular choice and well-defined procedure in the literature ${ }^{6,7}$. It is based on the location and size of the defect, availability of the local and pedicled options, clinical condition, and prognosis of the patient ${ }^{5}$. The latissimus dorsi muscle, pectoralis major muscle, rectus abdominis muscle, external oblique muscle, and serratus anterior muscle can be used as a source of these flaps ${ }^{5,8,9}$. The latissimus dorsi flap, though its large size and ability to rotate in a wide arc, provides only a limited part of cutaneous tissue with a width of $7-10 \mathrm{~cm}$ if the primary closure of the donor site is intended ${ }^{5}$. The pectoralis major muscle flap can be harvested with or without cutaneous paddle, but bilateral harvesting may be required in wider defects 5 . The rectus abdominis muscle flap may led to donor site morbidity such as abdominal wall hernia, and negatively affect early post-operative breathing ${ }^{5}$. Although the serratus anterior muscle can be used alone for anterior-lateral and posterior-lateral chest wall defects, it must be used with other flaps to reconstruct massive chest wall defects ${ }^{10,11}$. The external oblique muscle flap is not preferred as often as other pedicled flaps ${ }^{5}$. The patients, who undergo chest wall reconstruction with pedicled flaps, have a diminished tolerance to complications ${ }^{6}$. Thus, they may require challenging procedures, such as microsurgical augmentation of the compromised flaps ${ }^{6}$.

The microvascular free flaps may be mandatory if the required pedicled or local flaps are inadequate in size, or are unavailable, or not have ability to reach some areas such as thoraco-abdominal defects ${ }^{5}$. Tensor fascia lata flap, anterolateral thigh flap, latissimus dorsi flap, rectus abdominis flap, deep inferior epigastric perforator flap, fillet forearm flap, and omentum flap can be used as a source of microvascular free flaps. Microsurgical procedures must be performed quickly and sometimes require more than one team. If vessels are not available or are of inadequate diameter more challenging procedures are required ${ }^{12}$.

In cases, which develop secondary to malignancy, patient comorbidity and metastatic foci have to be taken into consideration before the surgery is undertaken, and surgical modalities to be applied have to be determined according to their both advantages and disadvantages. Thoracoepigastric flap is a technically simple procedure for soft-tissue closure with adequate coverage compared to pedicled muscle or myocutaneous flaps ${ }^{3}$, or microsurgical flaps and can be applied quickly, that is why we chose this technique. Challenging procedures, such as microsurgery, may not be tolerated in patients with comorbid and/or metastatic diseases. Considering this fact, we applied thoracoepigastric flaps, although they have their own disadvantages. They are rarely used for reconstruction of the large chest wall defects due to potential for necrosis and delayed wound healing ${ }^{2}$. The literature usually focuses on case series (2-29 cases) involving fasciocutaneous and thoracoepigastric flaps for chest wall reconstruction ${ }^{3,13-16}$. The degree of elevation of the flap depends on the size of the chest wall defect. These studies defined vertical boundary as the mammary fold and the second intercostal space and horizontal boundary as the middle axillary line and the middle sternal line ${ }^{3,13-16}$. Anatomic boundaries of tumor resection were more extended in our cases than ones in the previous studies, thus, required more dissection with larger sized flaps. Previous reports defined the anterior axillary line as the end of the axial pattern of the flap ${ }^{3,13-16}$. Thoracoepigastric flaps were more like random flaps with diminished vasculature, if it extended toward the posterior axillary line. Although it was not certain, flaps length-width ratios exceeding 1.5:1 were not recommended by those researches. They also concluded that broader based flaps ensure more perforators but restrict the arc of rotation,13-16. To promote greater arc of rotation, we extended the flap incision toward to the posterior axillary line laterally and to the ASIS, even below the ASIS in one patient, inferiorly. This study was unique in extended dissection boundaries, consequently managing the supposed risk of necrosis with conservative therapy or application of NPWT. To the best of our knowledge, Case III was also the first report that extended thoracoepigastric flap was applied bilaterally at the same session. Burattini et al. stated that one of their patients with bilateral breast cancer underwent two separate procedures with thoracoepigastric flaps at different periods ${ }^{3}$.

The NPWT promotes wound healing by applying subatmospheric pressure through a special sealed vacuum system, which consists of a suction pump, tubing and a dressing, to remove excess exudate, and 
increase blood supply ${ }^{17}$. It was used to overcome the distal flap necrosis in two patients. In one patient, necrosis resolved within 2 weeks, while in other it took 4 weeks to obtain a clean granulation tissue matrix. Case III, morbidly obese-diabetic woman, had undergone extended flap dissection leading to increased exudate production. Management of the wound exudate was a challenge. Despite application of NPWT, high level of exudate caused a delay in wound healing in Case III. In both patients, necrosis resolved completely and granulation tissue matrix filled the wounds, which led to heal by second intention. In none of them advanced surgical procedure (skin graft and/or flap) was required. Daily dressings were sufficient for healing.

Plastic surgeons use the concept of a "reconstructive ladder" in wound care, ranging from simple interventions (dressings, primary closure, etc.) to complex surgical interventions (pedicled and/or free flap), depending on the severity of the wounds ${ }^{18}$. Sometimes, wounds may left to heal by secondary intention, where the surface of the wounds are filled by granulation tissue. Healing by secondary intention may lead to contractures, scarring, restriction of movements and dehiscence, especially where the skin defects are too large. In order to prevent these complications skin grafts may be required ${ }^{18}$. In the current study, skin grafts were not applied on granulation tissue (Cases II and III). The wounds healed with daily dressings. None of these complications developed in Case II. In Case III, no wound complication developed within the early period of surgery. Although case III had a larger wound area, its linear configuration may have supported wound healing. Unfortunately, we could not follow-up her as she died within 3 months of surgery. Thus, we cannot make definitive comments on late complications.

This was a small case series without a comparator, and thus cannot be used to make conclusions on safety of the extended flap dissection.

\section{Conclusions}

Thoracoepigastric flaps can be used in large chest wall defects, especially in cases that develop secondary to trauma and infection, with functional and aesthetic results. In cases that develop secondary to malignancy, patient comorbidity and metastatic foci should be taken into consideration before the surgery is undertaken. Necrosis of the distal flap can be treated conservatively in cases where the necrosis size is small. The NPWT can eliminate the need for additional graft and/or flap surgery in patients with large necrosis size.

\section{Conflicts of interest}

The author reports no conflicts of interest.

\section{Ethical disclosures}

Protection of human and animal subjects. The author declares that no experiments were performed on humans or animals for this study.

Confidentiality of data. The author declares having followed the protocols in use at their working center regarding patients' data publication.

Right to privacy and informed consent. Patients were informed that their data could be used for research and informed consents were obtained from all patients before surgery. The corresponding author is in possession of this document.

\section{References}

1. Ertaş NM, Yüce $S$, Özpolat $B$, Çelebioğlu $S$. Göğüs ve karın ön duvarı rekonstrüksiyonlarında torakoepigastrik flep deneyimlerimiz. Turk J Plast Surg. 2005;13:170-4.

2. Matros E, Disa JJ. Uncommon flaps for chest wall reconstruction. Semin Plast Surg. 2011;25:55-9.

3. Burattini AC, Piteri RC, Ferreira LF, Silveira VF Jr., Broetto J, Richter CA, et al. Safety and viability of a new format of thoracoepigastric flap for reconstruction of the chest wall in locally advanced breast cancer: a cross-sectional study. Rev Bras Cir Plást. 2016;31:2-11.

4. Park JS, Ahn SH, Son BH, Kim EK. Using local flaps in a chest wall reconstruction after mastectomy for locally advanced breast cancer. Arch Plast Surg. 2015;42:288-94.

5. Salo J, Tukiainen E. Flap reconstruction of the chest wall after oncologic resection. Curr Challeng Thorac Surg. 2020;2:5.

6. Cordeiro PG, Santamaria E, Hidalgo D. The role of microsurgery in reconstruction of oncologic chest wall defects. Plast Reconstr Surg. 2001;108:1924-30.

7. Arnold PG, Pairolero PC. Chest wall reconstruction. Experience with 100 consecutive patients. Ann Surg. 1984;199:725-32.

8. Arnold PG, Pairolero PC. Chest-wall reconstruction: an account of 500 consecutive patients. Plast Reconstr Surg. 1996;98:804-10.

9. Chang RR, Mehrara BJ, Hu QY, Disa JJ, Cordeiro PG. Reconstruction of complex oncologic chest wall defects: a 10-year experience. Ann Plast Surg. 2004;52:471-9.

10. Arnold PG, Pairolero PC, Waldorf JC. The serratus anterior muscle: intrathoracic and extrathoracic utilization. Plast Reconstr Surg. 1984;73:240-8.

11. Althubaiti G, Butler CE. Abdominal wall and chest wall reconstruction. Plast Reconstr Surg. 2014;133:688e-701.

12. Sauerbier M, Dittler S, Kreutzer C. Microsurgical chest wall reconstruction after oncologic resections. Semin Plast Surg. 2011;25:60-9.

13. Woods JE, Arnold PG, Masson JK, Irons GB, Payne WS. Management of radiation necrosis and advanced cancer of the chest wall in patients with breast malignancy. Plast Reconstr Surg. 1979;63:235-41.

14. Leinster SJ, Webster JT. Thoraco-abdominal and thoracoepigastric flaps: alternatives to skin grafting after mastectomy. Clin Oncol. 1982;8:145-8.

15. Davis WM, McCraw JB, Carraway JH. Use of a direct, transverse, thoracoabdominal flap to close difficult wounds of the thorax and upper extremity. Plast Reconstr Surg. 1977;60:526-33.

16. Tai $Y$, Hasegawa $H$. A transverse abdominal flap for reconstruction after radical operations for recurrent breast cancer. Plast Reconstr Surg. 1974;53:52-4.

17. Capobianco CM, Zgonis T. An overview of negative pressure wound therapy for the lower extremity. Clin Podiatr Med Surg. 2009;26:619-31.

18. Boyce DE, Shokrollahi K. Reconstructive surgery. BMJ. 2006;332:710-2. 